\title{
BMJ Open Classic e-Delphi survey to provide national consensus and establish priorities with regards to the factors that promote the implementation and continued development of non-medical prescribing within health services in Wales
}

\author{
Molly Courtenay, ${ }^{1}$ Rhian Deslandes, ${ }^{2}$ Gail Harries-Huntley, ${ }^{3}$ Karen Hodson, ${ }^{4}$ \\ Gary Morris ${ }^{5,6}$
}

To cite: Courtenay M, Deslandes R, Harries-Huntley G, et al. Classic e-Delphi survey to provide national consensus and establish priorities with regards to the factors that promote the implementation and continued development of non-medical prescribing within health services in Wales. BMJ Open 2018;8:e024161. doi:10.1136/ bmjopen-2018-024161

- Prepublication history for this paper is available online. To view these files, please visit the journal online (http://dx.doi. org/10.1136/bmjopen-2018024161).

Received 12 May 2018 Revised 9 July 2018 Accepted 18 August 2018

Check for updates

(C) Author(s) (or their employer(s)) 2018. Re-use permitted under CC BY-NC. No commercial re-use. See rights and permissions. Published by BMJ.

For numbered affiliations see end of article.

Correspondence to Professor Molly Courtenay; courtenaym@cardiff.ac.uk

\section{ABSTRACT}

Objective To provide national consensus and establish priorities with regards to the factors that promote the implementation and continued development of nonmedical prescribing within health services.

Design Classic e-Delphi survey.

Setting National study in Wales.

Participants Pharmacists, nurses and allied health professionals with the independent/supplementary prescribing qualification.

Results A total of 55 non-medical prescribers agreed to become members of the expert panel of whom 42 (76\%) completed the round 1 questionnaire, 40/42 (95\%) completed round 2 and 34/40 (85\%) responded to round 3 . Twenty-one statements were developed, and consensus was achieved on nine factors representing those necessary for the successful implementation of non-medical prescribing and five representing actions required for its continued development. Strategic fit between non-medical prescribing and existing service provision, organisation preparedness, visible benefits, good managerial and team support, and a clear differentiation of roles were each important influences.

Conclusion Given the high degree of consensus, this list of factors and actions should provide guidance to managers and commissioners of services wishing to initiate or extend non-medical prescribing. This information should be considered internationally by other countries outside of the UK wishing to implement prescribing by non-medical healthcare professionals.

The aim of this study was to provide national consensus and establish priorities with regards to the factors that promote the implementation and continued development of non-medical prescribing within health services in Wales.
Strengths and limitations of this study

- Although our survey included responses from the full range of non-medical healthcare professionals who can prescribe medicines, only small numbers of respondents were pharmacists and allied health professionals, and our results may therefore reflect a nursing perspective not applicable to all non-medical prescribers.

- Most expert panel members worked in secondary care and in-hospital or outpatient services and so may not be reflective of the views of non-medical prescribers working in other settings/services.

- We acknowledge that for care to be patient centred, patients should participate in healthcare research; however, patients were not included as expert panel members.

\section{INTRODUCTION}

Globally, healthcare systems are implementing strategies, including expanded scopes of practice for healthcare professionals, to improve healthcare delivery. One such example is the expanded scope of practice by non-medical healthcare professionals (including nurses, pharmacists and allied health professionals (AHPs)) to include prescribing capability. Nurses and pharmacists in several countries including Canada, Sweden, New Zealand, the Netherlands, Ireland, Australia, USA and UK can now prescribe medicines. ${ }^{1-4}$ Faster and more efficient access to medicines, a need to address doctor shortages, the development of advanced practitioner roles and more 
effective use of healthcare professionals' knowledge and skills are each drivers for this role. ${ }^{1}$

In the UK, appropriately qualified registered nurses, pharmacists and AHPs can prescribe any medicine within their area of competence both independently (ie, responsible for the assessment, diagnosis and decisions about the clinical management required in patients with diagnosed or undiagnosed conditions $)^{5}$ or via supplementary prescribing. ${ }^{6}$ Supplementary prescribing comprises a written agreement, between the doctor, patient and supplementary prescriber, on the medicines the supplementary prescriber can prescribe.

The model of prescribing training in the UK, which is government funded, typically 6 months in duration, and only requiring applicants to be at degree level, ${ }^{7}$ has facilitated the rise in non-medical prescriber (NMP) numbers over the last 5 years. ${ }^{8}$ Around 32000 nurses, 4000 pharmacists and 1000 AHPs and optometrists have independent and supplementary prescribing capability. ${ }^{8}$ This represents about $5 \%$ of the UK nursing workforce, $7 \%$ of the pharmacy workforce and between $1 \%$ and $2 \%$ of the AHP workforce eligible to prescribe. These prescribers work in a variety of healthcare settings (including primary and secondary care) and prescribe medicines across a broad range of therapeutic areas. ${ }^{9-11}$ NMPs are safe, ${ }^{10} 12$ clinical and patient reported outcomes are comparable with medical prescribers ${ }^{1314}$ and stakeholders are satisfied reporting increased accessibility of services. ${ }^{15}{ }^{16}$ Furthermore, findings of an economic evaluation of NMPs in the North West of England ${ }^{17}$ identified that in terms of impact on patient outcomes, each of the 1566 NMP participants contributed an average added value of nearly $£ 1500$ over a 1-month period, that is, together a total of $£ 2.7$ million for the month.

Despite this evidence, national evaluations report that non-medical prescribing has been implemented inconsistently across Clinical Commissioning Groups and health boards (HBs) within the UK, and there is great variance with regards to the numbers of prescribers working within HBs/National Health Service Trusts, the numbers working within healthcare teams and the range of services and roles in which NMPs work. ${ }^{9} 101819$

These variations may lead to significant differences in the experiences of service users and have a differential effect on the workforce, with some non-medical healthcare professionals expected to integrate prescribing into their clinical practice in some organisations, while prescribing remains the domain of doctors in others.

There is some evidence available that has explored the factors that influence the use of prescribing by specific healthcare professional groups. For example, strong relationships with other prescribers ${ }^{20} 21$ and the importance of trust in these relationships ${ }^{22}$ have been reported to influence the integration of prescribing into practice by nurses. There is also evidence available that has examined the implementation of prescribing by specific healthcare professional groups working in certain services and settings. For example, nurse prescribing has been reported to be successfully implemented in diabetes service delivery because of the established roles nurses already have within diabetes teams and the strong collaborative working that is already in place. ${ }^{23}$ Pharmacists have described how implementation is smoother when prescribing is introduced into pre-existing structures and care arrangements, thus facilitating tasks already performed prior to its implementation. ${ }^{24}{ }^{25}$ However, it would be a useful exercise to identify the key factors that promote the implementation of NMP that can be applied to all NMP groups and the different services and settings within which they work. This would provide useful guidance to those wishing to initiate or extend NMP and help to promote consistency across services.

The aim of this study was to provide national consensus and establish priorities with regards to the factors that promote the implementation and continued development of non-medical prescribing within health services in Wales.

\section{METHODS \\ Design}

Where there is a dearth of research evidence and a desire to reach consensus, formal or structured methods are commonly used.$^{26}$ A commonly used formal consensus method is the Delphi technique. This technique uses rounds of questionnaires to collect data and achieve group consensus. ${ }^{27}$

A classic Delphi survey ${ }^{28} 29$ was adopted whereby round 1 of the Delphi survey involved item generation, that is, the first questionnaire contained open-ended questions inviting participants to provide their views on the factors that promote the implementation and development of non-medical prescribing within health services in Wales from which subsequent questionnaires were developed.

\section{Recruitment}

Experts, as opposed to a random sample representative of the target population, are employed as panel members in the Delphi technique, and it is recommended that explicit criteria are used to select panel members. ${ }^{30}$ 'Expert' in this study was defined as a pharmacist, nurse or AHP with the independent and supplementary prescribing qualification.

Purposive sampling was used to recruit a panel reflecting the range of non-medical healthcare professionals able to prescribe medicines using independent and supplementary prescribing. To ensure the full range of these healthcare professionals were included on the panel and that they were representative of independent/supplementary prescribers across Wales, all participants who had recently completed a national non-medical prescribing survey $(n=379)^{11}$ were invited to contact the researchers if they were interested in becoming an expert member of the Delphi panel.

There is no agreement within the literature as to the best number of participants to include in a Delphi 
Table 1 Non-medical prescribers who responded to each round

\begin{tabular}{|c|c|c|c|c|c|c|}
\hline \multirow[b]{2}{*}{ NMP } & \multicolumn{2}{|c|}{$\begin{array}{l}\text { Round } 1 \\
n=42\end{array}$} & \multicolumn{2}{|c|}{$\begin{array}{l}\text { Round } 2 \\
n=40\end{array}$} & \multicolumn{2}{|c|}{$\begin{array}{l}\text { Round } 3 \\
n=34\end{array}$} \\
\hline & $\mathbf{n}$ & $\%$ & $\mathbf{n}$ & $\%$ & $\mathbf{n}$ & $\%$ \\
\hline Nurse & 35 & 63.6 & 33 & 60 & 28 & 51.0 \\
\hline Pharmacist & 4 & 7.3 & 4 & 7.3 & 3 & 5.5 \\
\hline Physiotherapist & 2 & 3.6 & 2 & 3.6 & 2 & 3.6 \\
\hline Radiographer & 1 & 1.9 & 1 & 1.9 & 1 & 1.9 \\
\hline
\end{tabular}

NMP, non-medical prescriber.

survey. ${ }^{27}$ Although a large expert panel is recommended ${ }^{31}$ for heterogenous samples, it is unclear what constitutes large. Therefore, we included all NMPs who were keen to take part and fulfilled our definition of 'expert'. Seventy NMPs expressed an initial interest to participate. Each was given a Participant Information Sheet and provided with the opportunity to address any queries they may have had with a researcher. Fifty-five NMPs agreed to take part. Return of completed questionnaires provided implied consent to participate

\section{Data collection}

The survey was conducted across three rounds. Bristol Online Survey-a tool for creating web surveys—was used to develop each round of the online questionnaire survey. A link to each survey was distributed via email to all participants followed by two reminder emails, at 1 week intervals, per survey round. Data collection took place between October 2016 and December 2016.

Round 1: elicitation of the factors and actions required to promote the implementation and continued development of non-medical prescribing in service delivery

Participants were asked to provide their views on the factors that promote the implementation and continued development of non-medical prescribing within health services in Wales. Participants were able to provide as

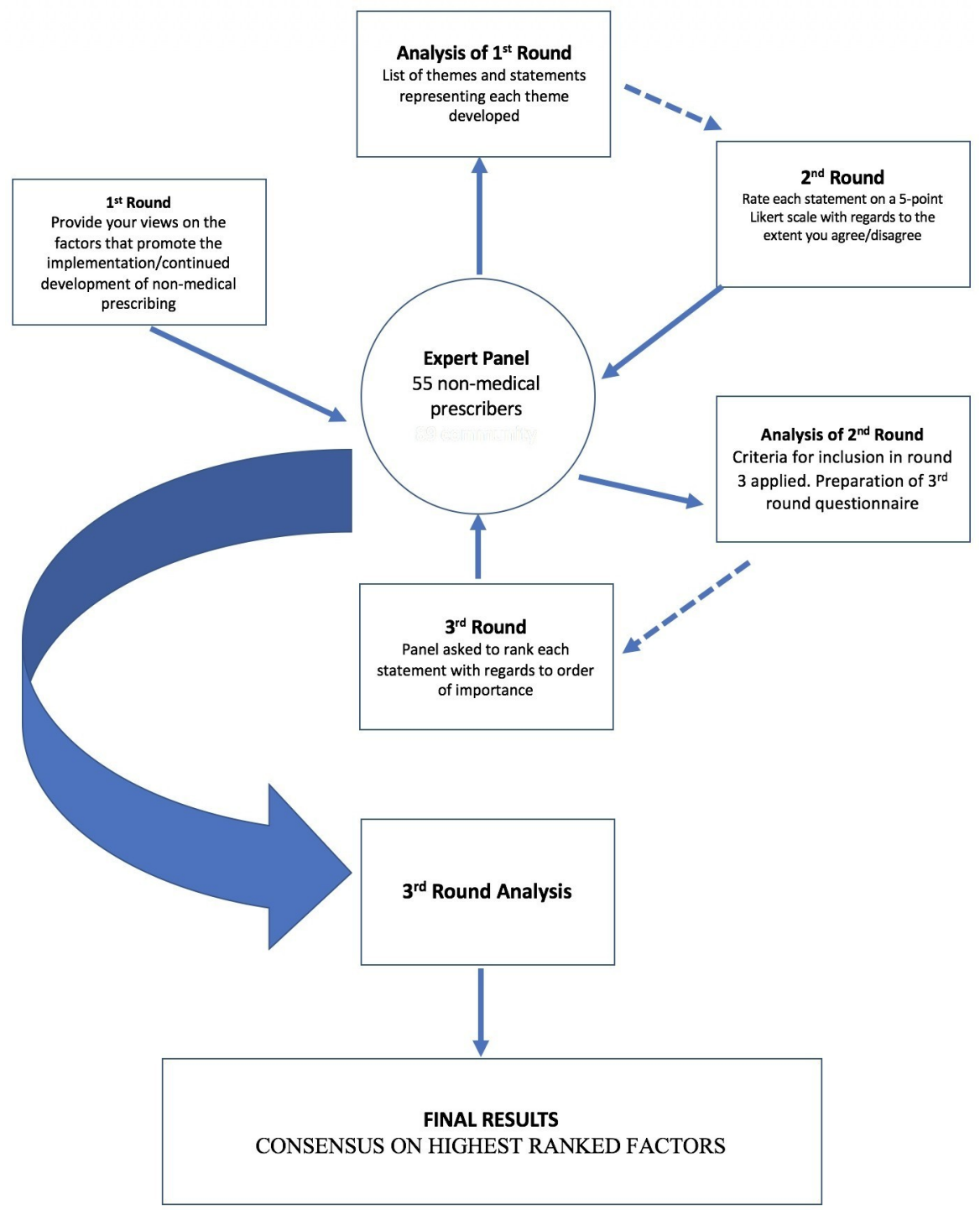

Figure 1 Summary of the Delphi process. 
Table 2 Demographic data of participants in round one survey

\begin{tabular}{|c|c|}
\hline & $\begin{array}{l}\text { Round } 1 \\
(n=42), n(\%)\end{array}$ \\
\hline \multicolumn{2}{|l|}{ Role $^{*}$} \\
\hline Specialist nurse & $21(50)$ \\
\hline Community nurse & $3(7)$ \\
\hline General practice nurse & $9(21)$ \\
\hline Senior clinical nurse & $2(5)$ \\
\hline Pharmacist & $4(10)$ \\
\hline Physiotherapist & $2(5)$ \\
\hline Radiographer & $1(2)$ \\
\hline \multicolumn{2}{|l|}{ Care setting } \\
\hline Primary & $6(14)$ \\
\hline Secondary & $20(48)$ \\
\hline Tertiary & $4(10)$ \\
\hline Community/intermediate & $3(7)$ \\
\hline More than one of the above & $9(21)$ \\
\hline \multicolumn{2}{|l|}{ Service provided } \\
\hline Hospital inpatient & $9(21)$ \\
\hline Hospital outpatient & $10(24)$ \\
\hline General practice & $4(10)$ \\
\hline Out of hours & $1(2 \%)$ \\
\hline Community/intermediate care & $3(7)$ \\
\hline More than one of the above & $15(36)$ \\
\hline \multicolumn{2}{|l|}{ Prescribing qualification } \\
\hline $\begin{array}{l}\text { Nurse independent/supplementary } \\
\text { prescriber }\end{array}$ & $35(83)$ \\
\hline $\begin{array}{l}\text { Pharmacist independent/supplementary } \\
\text { prescriber }\end{array}$ & $4(10)$ \\
\hline Physiotherapist supplementary prescriber & $1(2)$ \\
\hline $\begin{array}{l}\text { Physiotherapist independent/ } \\
\text { supplementary prescriber }\end{array}$ & $1(2)$ \\
\hline Radiographer supplementary prescriber & $1(2)$ \\
\hline
\end{tabular}

*Specialist nurses: (clinical nurse specialist, specialist nurse practitioner and nurse clinician); community nurses (team lead); general practice nurses (advanced nurse practitioner, practice nurses and nurse practitioners); senior clinical nurse (ward manager). Pharmacist: (senior clinical pharmacist, advanced practitioner and medicines management pharmacist); physiotherapist: (clinical specialist and advanced practitioner); radiographer.

much information as they wished within the free text space provided.

\section{Refining factors and actions}

The data were analysed by an experienced qualitative researcher using thematic analysis. ${ }^{32}$ Data were read, and words, phrases and sentences relating to the implementation and continued development of non-medical prescribing were identified. This information was then condensed and grouped into themes. This process was
Box 1 Factors that promote the implementation of nonmedical prescribing

- Team members, managers and those working in senior roles within the health board/trust/general practice need to recognise non-medical prescribing as a positive contributor to improve service efficiency.

- The successful implementation of non-medical prescribing requires that organisations are ready and prepared for this role, that is, structures and processes are in place that enable prescribing.

- It is important that the value of non-medical prescribing is demonstrated through patient satisfaction.

- Healthcare teams, managers and those responsible for service redesign and workforce planning need to understand the non-medical prescribing role and its potential.

- Both management and team support are required for the non-medical prescribing role to be fully implemented.

- It is important that there is a strategic fit between non-medical prescribing and existing service provision so that non-medical prescribing is seen as enhancing service efficiency rather than altering the structural organisation of care.

- Good interprofessional relationships are required in order to promote the necessary supportive culture for the acceptance of the non-medical prescribing role.

- Clinical supervision is essential for the successful implementation of non-medical prescribing.

- Continuing professional development is vital for the successful implementation of non-medical prescribing.

supported by the use of NVivo 10 qualitative data analysis software package. To cross-check data analysis and ensure data quality, consistency in approach and transparency of analytical decision making, $50 \%$ of the data were read and coded independently by a second experienced qualitative researcher. Differences in interpretation were resolved through discussion between the two researchers and the wider research team. A number of statements representing each theme were then developed.

\section{Round 2: building consensus}

An email was sent to members of the expert panel inviting them to participate in round 2 of the Delphi process. In this round, NMPs were asked to rate how much they agreed or disagreed with each of the statements developed in round 1, using a 5-point Likert scale (1=strongly disagree to 5 =strongly agree). Median scores and IQRs were calculated for responses to each statement to define at which point on the Likert scale $50 \%$ of the answers fell above and below.

IQRs that form the distance between the 25th and 75 th percentiles were used to represent the spread of the data and to assess the level of consensus per question. Responses where the median was greater than or equal to 4 (high level of agreement that the statement is important) with a small IQR (less than or equal to 1.5) were considered important statements that had reached consensus. Those with a median score less than or equal to 3.5, with a small IQR (less than or equal to 1.5), were considered to have reached consensus on a lack of 
Box 2 Actions required for the continued development of non-medical prescribing across health services

- Staff involved in strategic planning and policy development need to provide non-medical prescribers (NMPs) with timely, relevant, adequate and up-to-date information on legislation, policy and good practice surrounding prescribing and medicines management.

- NMPs should be involved in the development of prescribing and medicines management policies and guidelines.

- A consistent strategic approach to the implementation and progression of non-medical prescribing (ie, workforce planning, selection of candidates for training, provision of clinical supervision, continuing professional development (CPD) and organisational preparation for the role) is required.

- There is a need for improved access to clinical supervision.

- There is a need for improved peer support.

- There is a need for improved CPD.

- The non-medical prescribing qualification should be a job specification for certain roles (eg, advanced practitioner) and should not be lower than a Band 7.

- A proactive approach to succession planning needs to be adopted.

- Frontline practitioner prescribers in senior roles need to be involved in service redesign and workforce planning.

> Increased funding should be available for those wishing to undertake non-medical prescribing training.

- Study leave should be available for those wishing to undertake non-medical prescribing training.

- Clinical governance systems within which NMPs work need to be improved.

importance. All important statements that had reached consensus were taken forward to the third round.

Round 3: reaching consensus on priorities

In the final round, statements were randomly listed, and participants were asked to rank how much of a priority each statement was from 1 to 10 (where 1 was the most important and 10 was the least important). Participants were asked to use each number only once, leaving those that they felt were not so important blank. Responses were inversely scored and collated. Priorities were defined as those factors receiving the highest total scores.

\section{Patient and public involvement}

Patients were not involved in the development of the research question, outcome measures, design of the study or recruitment to, and conduct of, the study.

\section{RESULTS}

A total of 55 NMPs agreed to become members of the expert panel of whom $42(76 \%)$ completed round 1 questionnaire, 40/42 (95\%) completed round 2 and 34/40 $(85 \%)$ responded to round 3 . Table 1 provides a description of the different types of NMPs who responded to each round. Figure 1 provides a summary of each round of the Delphi process.

\section{Round 1}

Forty-two (76\%) participants responded to the initial survey. Most of these participants were nurses (see table 1).

Most respondents (20\% or $47 \%)$ worked in secondary care and provided hospital in-patient or out-patient services. The demographic characteristics of these participants are described in table 2.

Twenty-one statements were developed, that is, nine statements representing the factors that promote the implementation of non-medical prescribing, and 12 statements representing the actions required in order to continue its development (see box 1 and 2).

Table 3 Factors that promote the implementation of non-medical prescribing

\begin{tabular}{lll} 
& Median & IQR \\
\hline $\begin{array}{l}\text { Team members, managers and those working in senior roles within the health board/trust/general practice } \\
\text { need to recognise non-medical prescribing as a positive contributor to improve service efficiency. }\end{array}$ & 4.0 & 0.0 \\
$\begin{array}{l}\text { Healthcare teams, managers and those responsible for service redesign and workforce planning need to } \\
\text { understand the non-medical prescribing role and its potential. }\end{array}$ & 4.0 & 0.0 \\
$\begin{array}{l}\text { The successful implementation of non-medical prescribing requires that organisations are ready and prepared } \\
\text { for this role that is, structures and processes are in place that enable prescribing. }\end{array}$ & 0.5 \\
$\begin{array}{l}\text { Both management and team support are required for the non-medical prescribing role to be fully } \\
\text { implemented. }\end{array}$ & 4.0 \\
$\begin{array}{l}\text { It is important that there is a strategic fit between non-medical prescribing and existing service provision so } \\
\text { that it is seen as enhancing service efficiency rather than altering the structural organisation of care. }\end{array}$ & 4.0 \\
$\begin{array}{l}\text { Good interprofessional relationships are required in order to promote the necessary supportive culture for the } \\
\text { acceptance of the non-medical prescribing role. }\end{array}$ & 1.0 \\
$\begin{array}{l}\text { Clinical supervision is essential for the successful implementation of non-medical prescribing. } \\
\text { Continuing professional development is vital for the successful implementation of non-medical prescribing. }\end{array}$ & 4.0 \\
It is important that the value of non-medical prescribing is demonstrated through patient satisfaction. & 4.0 & 1.0 \\
\hline
\end{tabular}

*Shaded areas signify the factors that promote the implementation of non-medical prescribing within health services in Wales for which there was high level of agreement among panel members. 
Table 4 Actions required for the continued development of non-medical prescribing across health services

\section{Actions required for the continued development of non-medical prescribing across health services.}

\begin{tabular}{|c|c|c|}
\hline $\begin{array}{l}\text { Staff involved in strategic planning and policy development need to provide NMPs with timely, relevant, } \\
\text { adequate and up-to-date information on legislation, policy and good practice surrounding prescribing and } \\
\text { medicines management. }\end{array}$ & 3.0 & 1.0 \\
\hline NMPs should be involved in the development of prescribing and medicines management policies and guidelines. & 4.0 & 1.0 \\
\hline $\begin{array}{l}\text { A consistent strategic approach to the implementation and progression of non-medical prescribing (ie, } \\
\text { workforce planning, selection of candidates for training, provision of clinical supervision, CPD and organisational } \\
\text { preparation for the role) is required. }\end{array}$ & 4.0 & 1.0 \\
\hline Clinical governance systems within which NMPs work need to be improved. & 3.0 & 1.0 \\
\hline There is a need for improved peer support. & 3.0 & 1.0 \\
\hline There is a need for improved access to clinical supervision. & 3.0 & 1.25 \\
\hline There is a need for improved continuing professional development. & 3.0 & 1.25 \\
\hline $\begin{array}{l}\text { The non-medical prescribing qualification should be a job specification for certain roles (eg, advanced } \\
\text { practitioner) and should not be lower than a Band } 7 \text {. }\end{array}$ & 4.0 & 1.0 \\
\hline A proactive approach to succession planning needs to be adopted. & 4.0 & 1.0 \\
\hline Increased funding should be available for those wishing to undertake non-medical prescribing training. & 3.0 & 1.5 \\
\hline Frontline practitioner prescribers in senior roles need to be involved in service redesign and workforce planning. & 3.5 & 1.0 \\
\hline Study leave should be available for those wishing to undertake non-m & 4.0 & 1.0 \\
\hline
\end{tabular}

*Shaded areas signify the actions required for the continued development of non-medical prescribing within health services in Wales for which there was high level of agreement among panel members.

CPD, continuing professional development.

\section{Round 2}

Forty out of $42(95 \%)$ participants responded to the second round. See tables 3 and 4 for a description of the median scores and IQRs for each of the statements.

Participant responses showed a high level of importance across 14 of the statements (nine representing the factors that promote the implementation of non-medical prescribing and five statements representing the actions required in order to continue its development); each statement having a median greater than or equal to four and a IQR less than or equal to 1.5. There was consensus on a lack of importance across seven statements representing the actions required for the continued development of non-medical prescribing, that is, each statement had a score less than or equal to 3.5 and an IQR less than or equal to 1.5 .

\section{Round 3}

Thirty-four $(85 \%)$ participants responded to the third round. Statements representing factors that promote the implementation and continued development of non-medical prescribing are shown in priority order in tables 5 and 6 .

\section{Table 5 Factors that promote the implementation of non-medical prescribing in priority order}

\section{Rank Factor}

1 Clinical supervision is essential for the successful implementation of non-medical prescribing.

2 Continuing professional development is vital for the successful implementation of non-medical prescribing.

3 It is important that the value of non-medical prescribing is demonstrated through patient satisfaction.

4 Good interprofessional relationships are required in order to promote the necessary supportive culture for the acceptance of the NMP role.

5 It is important that there is a strategic fit between non-medical prescribing and existing service provision so that it is seen as enhancing service efficiency rather than altering the structural organisation of care.

$6 \quad$ Both management and team support are required for the NMP role to be fully implemented.

$7 \quad$ Healthcare teams, managers and those responsible for service redesign and workforce planning need to understand the NMP role and its potential.

8 The successful implementation of non-medical prescribing requires that organisations are ready and prepared for this role, that is, structures and processes are in place that enable prescribing.

9 Team members, managers and those working in senior roles within the health board/trust/general practice need to recognise non-medical prescribing as a positive contributor to improve service efficiency. 
Table 6 Actions required for the continued development of non-medical prescribing in priority order

\begin{tabular}{ll}
\hline Rank & Action \\
\hline 1 & A proactive approach to succession planning needs to be adopted. \\
2 & NMPs should be involved in the development of prescribing and medicines management policies and guidelines. \\
3 & $\begin{array}{l}\text { Study leave should be available for those wishing to undertake non-medical prescribing training. } \\
4\end{array}$ \\
$\begin{array}{l}\text { The non-medical prescribing qualification should be a job specification for certain roles (eg, advanced practitioner) and } \\
\text { should not be lower than a Band } 7 .\end{array}$ \\
$\begin{array}{l}\text { A consistent strategic approach to the implementation and progression of non-medical prescribing (ie, workforce } \\
\text { planning, selection of candidates for training, provision of clinical supervision, continuing professional development } \\
\text { and organisational preparation for the role) is required. }\end{array}$
\end{tabular}

\section{DISCUSSION}

\section{Statement of principal findings}

The aim of this study was to provide national consensus and establish priorities with regards to the factors that promote the implementation and continued development of non-medical prescribing within health services. A classic Delphi survey was adopted whereby round 1 of the survey rounds involved item generation, and this enabled panellists to reach a consensus, with consistent high levels of agreement reached, on 14 statements. Confidence in consensus resulted in a list of factors and actions, in priority order, that promote the implementation and continued development of non-medical prescribing within health services in Wales.

\section{Strengths and weaknesses}

The main strength of the work is that it is based on responses from a national panel of defined experts, had a good response rate and provides information on the factors that promote the implementation and continued development of non-medical prescribing within health services. However, some limitations also need to be recognised. First, the composition of the expert panel, with most experts being nurses, and only small numbers of respondents representing pharmacists and AHPs (ie, physiotherapists and podiatrists). Our results may therefore reflect a nursing perspective not applicable to all NMPs. Second, we could have included patients as members of the expert panel. We acknowledge that for care to be patient centred, patients need to participate in the research that informs healthcare decisions, however, given resource constraints and the, problems associated with large heterogenous samples (ie, difficulties surrounding data collection/analysis, reaching consensus and verifying results), ${ }^{28}$ only NMPs were included as panel members. Third, perceptions of factors that promote the implementation and development of non-medical prescribing may have been influenced by the setting/ services in which respondents worked. Most expert panel members worked in secondary care and hospital inpatient or outpatient services and so may not reflect the views of NMPs working in other settings/services. Fourth, it is important to recognise that the results of Delphi studies are 'group consensus' and not necessarily 'best', 'expert' or 'correct' results. ${ }^{29}$ Despite these limitations, this study has provided a list of factors, in priority order, that promote the implementation and continued development of non-medical prescribing within health services in Wales.

\section{Comparison with other studies}

The extent to which there is a strategic fit between non-medical prescribing and existing service provision, and that non-medical prescribing is seen as enhancing service efficiency rather than altering the structural organisation of care, was viewed as a key factor that promoted its implementation. This aligns with research that has explored innovations in health services ${ }^{33}{ }^{34}$ innovations more likely to be adopted where there are clear advantages and few barriers to its adoption, and supports the findings of earlier studies in which researchers have investigated nurse and pharmacist prescribing. ${ }^{23-25}$ 35-37

Researchers exploring prescribing by nurses working in diabetes $^{23}$ and dermatology ${ }^{37}$ services delivery reported that pre-existing and established roles (including their involvement in medicines management activities such as medicines reviews and running clinics) facilitated the implementation of prescribing. Prescribing was viewed as improving service efficiency without the need to alter existing arrangements or roles. Similarly, prescribing by pharmacists ${ }^{24}$ has been reported to be successful where it helped them complete tasks to which they already contributed or performed in part. For example, prior to prescribing, medication was reported to be provided without a prescription. The ability to issue a prescription legitimised this practice and facilitated the completion of the task. ${ }^{24}$

The extent to which organisations are ready and prepared for non-medical prescribing was another important factor reported to promote its implementation. Processes such as access to clinical supervision and continuing professional development (CPD) were reported to be important influences. The availability of study leave to undertake prescribing training, the involvement of NMPs in the development of prescribing and medicines management policies and guidelines and a consistent strategic approach to the implementation of non-medical prescribing were each reported actions required for its continued development in Wales. Our findings are consistent with research reporting on a 
national evaluation of physiotherapist and podiatrist prescribers. ${ }^{38}$ These researchers reported that in order to embed prescribing, there is a need for a clear NMP strategy at an organisational level. The findings also concur with research involving nurse and pharmacist prescribers. As with the findings in this study, pharmacists have been found to be more likely to prescribe when they have access to clinical information, and up-to-date prescribing policies were in place. ${ }^{39}$ Similarly, access to CPD has been reported to encourage prescribing by nurses. ${ }^{21}{ }^{40}$ Furthermore, where prescribing has been introduced to nurses working in well-established roles, this has been reported to have helped its successful implementation, as conditions such as CPD and access to clinical supervision are already in existence. ${ }^{23}$

Visible benefits were reported to be another important influence on the implementation of prescribing. Benefits included patient satisfaction and the need for non-medical prescribing to be recognised as a positive contributor to enhance service efficiency. Similarly, visible benefits including perceived improvements to patient care have been reported to facilitate the adoption of prescribing by nurses ${ }^{36}$ and convenience for both patients and pharmacists have been reported to encourage prescribing by pharmacists. ${ }^{24}$

Good managerial and team support, good interprofessional relations and a clear differentiation of roles (the non-medical prescribing qualification was viewed as a job specification for advanced practitioner roles) were also other important influences. This is consistent with findings of previous research in which a receptive context for change, that is, a history of collaborative working, was reported to have paved the way for good relations between nurse prescribers and doctors, with the promotion of the supportive culture necessary for acceptance of the prescribing role. ${ }^{23}$ More recently, the influence of professional relationships on the prescribing boundaries of nurses, and the integration of prescribing by nurses into practice, has been highlighted. ${ }^{22}$ Similarly, pharmacists have also reported that the nature and extent of pharmacist prescriber relations with physicians has a substantial influence on whether or not they prescribe, many pharmacists expressing a reluctance to prescribe when they believed the physician was unsupportive. ${ }^{39}$ It is interesting to note that the prescribing qualification was seen as a job specification for advanced practitioner roles and viewed as no lower than a band 7. New UK standards for prescribing education for nurses will enable first-level registered nurses with only 1 year qualified experience (and so likely to be lower than a band 7) to access the prescribing programme. ${ }^{41}$

\section{Meaning of the study: possible explanations and implications for clinicians and policy makers}

It is evident that non-medical prescribing has been implemented inconsistently across health services in Wales. ${ }^{11}$ The findings of this study provide guidance to managers and commissioners of services wishing to implement non-medical prescribing in new areas of practice, or,further develop services already in existence. This will help to promote consistency across services. The findings also provide guidance for countries outside of the UK wishing to implement non-medical prescribing, although their origin from a UK perspective means there is a need for adaptation to other healthcare systems.

\section{Unanswered questions and future research}

Research designed to test and refine the factors identified by expert members would be helpful. Testing these factors in different contexts and across different non-medical prescriber groups would also be useful, as barriers and facilitators to non-medical prescribing implementation may differ in emphasis across services and professions.

\section{CONCLUSION}

Given the high degree of consensus, this list of factors and actions should provide guidance to managers and commissioners of services wishing to initiate or extend non-medical prescribing. This information should be considered internationally by other countries outside of the UK wishing to implement prescribing by non-medical healthcare professionals.

\section{Author affiliations}

${ }^{1}$ School of Healthcare Sciences, Cardiff University, Cardiff, UK

${ }^{2}$ Cardiff School of Pharmacy and Pharmaceutical Sciences, Cardiff University, Cardiff, UK

${ }^{3}$ Workforce Education and Development Service, NHS Wales Shared Services Partnership, Cardiff, UK

${ }^{4}$ School of Pharmacy and Pharmaceutical Sciences, Cardiff University, Cardiff, UK ${ }^{5}$ School of Healthcare Sciences, Cardiff University \& HyweIDda University Health Board, Carmarthen, SA31, Cardiff University, Cardiff, UK

${ }^{6}$ Advanced Physiotherapy Practitioner, Hywel Dda University Health Board, Carmarthen, UK

Acknowledgements We are grateful to all the NMPs who participated in the research. Without their participation, this work would not have been possible. We are also grateful to Discover Research and Design Ltd, who assisted with the data collection and analysis, and to Victoria Shepherd, Centre for Trials Research, Cardiff University, for her advice with regards to the Delphi process

Contributors MC made a substantial contribution to the conception and design of the work, the acquisition and interpretation of data and drafting of the work. $\mathrm{RD}, \mathrm{GH}-\mathrm{H}, \mathrm{KH}$ and $\mathrm{GM}$ made a substantial contribution to the design of the work, acquisition, analysis and interpretation of data. All authors critically revised drafts of the work and approved the final version to be published and agree to be accountable for all aspects of the work in ensuring that questions related to the accuracy or integrity of any part of the work are appropriately investigated and resolved.

Funding The authors have not declared a specific grant for this research from any funding agency in the public, commercial or not-for-profit sectors.

\section{Competing interests None declared.}

Patient consent Obtained.

Ethics approval Ethical approval for the study was provided by the School of Healthcare Sciences Research Governance and Ethics Committee, Cardiff University (reference number 391REC).

Provenance and peer review Not commissioned; externally peer reviewed. Data sharing statement No additional data available.

Open access This is an open access article distributed in accordance with the Creative Commons Attribution Non Commercial (CC BY-NC 4.0) license, which 
permits others to distribute, remix, adapt, build upon this work non-commercially, and license their derivative works on different terms, provided the original work is properly cited, appropriate credit is given, any changes made indicated, and the use is non-commercial. See: http://creativecommons.org/licenses/by-nc/4.0/.

\section{REFERENCES}

1. Kroezen M, van Dijk L, Groenewegen PP, et al. Nurse prescribing of medicines in Western European and Anglo-Saxon countries: a systematic review of the literature. BMC Health Serv Res 2011;11:11-27.

2. Pharmacy council of new zealand. 2010 http://www. pharmacycouncil.org.nz/prescriber (accessed 19 Fed 2016).

3. Canadian Pharmacist Association.2016. https://www.pharmacists. ca/pharmacy-in-canada/scope-of-practice-canada/ (accessed 19 Feb 2016).

4. Controlled Drugs and Substances Act. New Classes of Practitioners Regulations SOR/2012-230;2012;146. http://canadagazette.gc.ca/ rp-pr/p2/2012/2012-11-21/html/sor-dors230-eng.html

5. DoH: Patients to get quicker access to medicines (Press Release). London: DH, 2001.

6. DoH: Supplementary Prescribing. London: DH, 2005.

7. DoH: Improving patient's access to medicines: A guide to implementing nurse and pharmacist independent prescribing within the NHS in England. London: DoH, 2006.

8. Do H. Personal communication, 2017.

9. Courtenay M, Carey N, Stenner K. An overiew of non medical prescribing across one strategic health authority: a questionnaire survey. BMC Health Serv Res 2012;12:138.

10. Latter S, Blenkinsopp A, Smith A, et al. Evaluation of nurse and pharmacist independent prescribing: University of Southampton and University of Keele on behalf of the DoH, 2010.

11. Courtenay M, Khanfer R, Harries-Huntly G, et al. Overview of the uptake and implementation of non-medical prescribing in Wales: a national survey. BMJ Open 2017;7:e015313.

12. Latter S, Maben J, Myall M, et al. An Evaluation of Extended Formulary Independent Nurse Prescribing. UK: Final Report. Policy Research Programme Department of Health \& University of Southampton, 2005

13. Weeks G, George J, Maclure K, et al. Non-medical prescribing versus medical prescribing for acute and chronic disease management in primary and secondary care. Cochrane Database Syst Rev 2016;11:CD011227.

14. Gielen SC, Dekker J, Francke AL, et al. The effects of nurse prescribing: a systematic review. Int J Nurs Stud 2014;51:1048-61.

15. Stenner KL, Courtenay M, Carey N. Consultations between nurse prescribers and patients with diabetes in primary care: A qualitative study of patient views. Int J Nurs Stud 2011;48:37-46.

16. Carey N, Stenner K, Courtenay M. Stakeholder views on the impact of nurse prescribing on dermatology services. J Clin Nurs 2010;19(34):498-506.

17. i5 report (2015) NMP an economic evaluation. Health education north west.

18. National Prescribing Centre. Non-medical prescribing: A quick guide for commissioners. 2010. National Prescribing Centre.

19. Dobel-Ober D, Brimblecombe N. National survey of nurse prescribing in mental health services; a follow-up 6 years on. J Psychiatr Ment Health Nurs 2016;23(6-7):378-86.
20. Lim AG, North N. \& Shaw J. Beginners in prescribing practice: Experiences and perceptions of nurses and doctors. Journal of Clinical Nursing 2018:1-10.

21. Creedon R, Byrne S, Kennedy J, et al. The impact of nurse prescribing on the clinical setting. Br J Nurs 2015;24:878-85.

22. Bowskill D, Timmons S, James V. How do nurse prescribers integrate prescribing in practice: case studies in primary and secondary care. J Clin Nurs 2013;22:2077-86.

23. Stenner K, Carey N, Courtenay M. Implementing nurse prescribing: a case study in diabetes. J Adv Nurs 2010;66:522-31.

24. Makowsky MJ, Guirguis LM, Hughes CA, et al. Factors influencing pharmacists' adoption of prescribing: qualitative application of the diffusion of innovations theory. Implement Sci 2013;8:109.

25. Dawoud D, Griffiths P, Maben J, et al. Pharmacist supplementary prescribing: a step toward more independence? Res Social Adm Pharm 2011;7:246-56.

26. Keeney S, Hasson F, McKenna HP. A critical review of the Delphi technique as a research methodology for nursing. Int J Nurs Stud 2001;38:195-200.

27. Keeney S, Hasson F, McKenna H. Consulting the oracle: ten lessons from using the Delphi technique in nursing research. J Adv Nurs 2006;53:205-12.

28. Hasson F, Keeney S, McKenna H. Research guidelines for the Delphi survey technique. J Adv Nurs 2000;32:1008-15.

29. Day J, Bobeva M. A generic toolkit for the successful management of Delphi studies. Electron J Bus Res Methodol 2005;3:103-16.

30. Trevelyan EG, Robinson N. Delphi methodology in health research: how to do it? European Journal of Integrative Medicine 2015;7:423-8.

31. Skulmoski GJ, Hartman FT, Krahn J. The Delphi methods for graduate research. J Inf Technol Educ 2007;6:1-21.

32. Braun V. \& Clarke V. Using thematic analysis in psychology. Qualitative research in psychology 2006;3:77-101.

33. Rogers EM. Diffusion of innovations. 5th ed. New York: Free Press/ Simon and Schuster, 2003.

34. Greenhalgh T, Robert G, Macfarlane F, et al. Diffusion of innovations in service organizations: systematic review and recommendations. Milbank Q 2004;82:581-629.

35. Tully MP, Latif S, Cantrill JA, et al. Pharmacists' changing views of their supplementary prescribing authority. Pharm World Sci 2007;29:628-34.

36. Stenner KL, Courtenay M, Cannons K. Nurse prescribing for inpatient pain in the United Kingdom: a national questionnaire survey. Int $J$ Nurs Stud 2011;48.

37. Stenner K, Courtenay M, Carey NJ. Doctor and non nurse prescriber views about nurse prescribing: Results from a case study in dermatology. Journal of Advanced Nursing 2009;65:851-9.

38. Carey N, Stenner K, Moore A, et al; Evaluation of Physiotherapist and Podiatrist Independent Prescribing, Mixing of Medicines, and Prescribing of Controlled Drugs Policy Research Programme: Department of Health, 2017.

39. Bourne RS, Baqir W, Onatade R. Pharmacist independent prescribing in secondary care: opportunities and challenges. Int $J$ Clin Pharm 2016;38:1-6.

40. Scrafton J, McKinnon J, Kane R. Exploring nurses' experiences of prescribing in secondary care: informing future education and practice. J Clin Nurs 2012;21:2044-53.

41. NMC, 2018. Standards for prescribing programmes https://www. nmc.org.uk/standards/standards-for-post-registration/standards-forprescribers/standards-for-prescribing-programmes/ 